Case Report

\title{
A Case of Dermatomyositis and Anti-EJ Autoantibody with Chronic Intestinal Pseudoobstruction Successfully Treated with Octreotide
}

\author{
Chiho Yamada, ${ }^{1}$ Shinji Sato, ${ }^{1}$ Noriko Sasaki, ${ }^{2}$ Takayoshi Kurabayashi, ${ }^{1}$ Sho Sasaki, \\ Yasushi Koyama, ${ }^{1}$ Naofumi Chinen, ${ }^{1}$ Takayuki Wakabayashi, ${ }^{2}$ and Yasuo Suzuki ${ }^{1}$ \\ ${ }^{1}$ Division of Rheumatology, Department of Internal Medicine, Tokai University, School of Medicine, Isehara 259-1193, Japan \\ ${ }^{2}$ Division of Rheumatology, Department of Internal Medicine, Tokai University Hachioji Hospital, Hachioji, Japan
}

Correspondence should be addressed to Shinji Sato; shinsjam@tokai-u.jp

Received 6 September 2016; Accepted 10 October 2016

Academic Editor: Mehmet Soy

Copyright (c) 2016 Chiho Yamada et al. This is an open access article distributed under the Creative Commons Attribution License, which permits unrestricted use, distribution, and reproduction in any medium, provided the original work is properly cited.

\begin{abstract}
Chronic intestinal pseudoobstruction (CIPO) is a serious complication in patients with connective tissue disease (CTD) and is sometimes life-threatening or fatal despite intensive medical treatment. Here, we report a patient with dermatomyositis (DM) and anti-EJ autoantibody who developed CIPO that was improved by octreotide. Because her abdominal pain and bloatedness were so severe and persistent, we introduced octreotide to relieve symptoms. In this case, continuous intravenous administration as well as long-acting subcutaneous injection of octreotide was effective for treating CIPO.
\end{abstract}

\section{Introduction}

Dermatomyositis (DM) is a systemic connective tissue disease characterized mainly by proximal muscle weakness and myalgia with typical skin rash (i.e., heliotrope rash or Gottron's papule) [1]. Chronic intestinal pseudoobstruction (CIPO) is a gastrointestinal disorder that resembles a mechanical obstruction of the bowels but without any physical blockage, and which is due to abnormalities of peristalsis [2]. Imaging reveals dilation of the small and large bowels with air-fluid levels. Connective tissue disease (CTD), particularly systemic sclerosis (SSc), is one of the underlying conditions associated with CIPO [3], whereas this syndrome is relatively rarely a complication of polymyositis (PM)/DM or systemic lupus erythematosus (SLE). To the best of our knowledge, for the first time, here we report a DM patient with anti-EJ autoantibody whose refractory CIPO was improved with octreotide. In this case, continuous intravenous administration with subsequent subcutaneous injection of octreotide was effective for amelioration of her abdominal symptoms.

\section{Case Report}

A 38-year-old woman who was suspected of having interstitial lung disease (ILD) was referred to our hospital in July 2004. At that time, she had fever, heliotrope rash, and Gottron's papules and suffered from polyarthralgia and proximal muscle weakness. Laboratory examination revealed high serum creatine kinase (CK) levels and chest X-rays showed reticular and granular shadows on lower lung fields. On this basis, she was diagnosed as having DM with ILD and was hospitalized for initiation of treatment with $50 \mathrm{mg}$ of prednisolone (PSL) daily. As her muscle symptoms and serum CK level improved, PSL was gradually tapered. In June 2006, when the PSL dose was down to $10 \mathrm{mg}$ daily, her muscle weakness recurred. At the same time, she noticed a feeling of abdominal fullness and severe pain all over the abdomen; she was rehospitalized for further examination and treatment. Her abdomen was distended and tympanitic on percussion and bowel sound was absent on auscultation. Abdominal Xray, CT, and endoscopy with a lower gastrointestinal tract fiberscope revealed an intestinal obstructive ileus with no discernible mechanical cause, leading to a diagnosis of CIPO. 
She was treated with conservative medical management using $20 \mathrm{mg}$ of PSL, which gradually improved her symptoms. However, from this time on, she suffered sporadic persistent bloatedness and/or abdominal pain without the worsening of muscle or respiratory symptoms. In January 2012, she again suffered muscle weakness, dyspnea, and abdominal bloating and pain while taking $9 \mathrm{mg}$ of PSL. She was urgently readmitted to our hospital. At admission, she had fever, proximal muscle weakness, myalgia, and dyspnea on exertion and arterial oxygen saturation decreased to $93 \%$ under oxygen inhalation $\left(\mathrm{FiO}_{2}\right.$ was 0.35$)$. Fine crackles were heard in both lower lung fields. The abdomen was distended and tenderness was present all over it. Bowel movement was hypoactive and a tympanitic percussion note was heard. Laboratory findings were white blood cell count $19,800 / \mu \mathrm{L}$, red blood cell count $546 \times 10^{6} / \mu \mathrm{L}$, hemoglobin $12.3 \mathrm{~g} / \mathrm{dL}$, and platelets at $43.5 \times$ $10^{4} / \mu \mathrm{L}$. Serum AST was $37 \mathrm{IU} / \mathrm{L}$, ALT was $42 \mathrm{IU} / \mathrm{L}, \mathrm{LDH}$ was $316 \mathrm{IU} / \mathrm{L}$, and creatine kinase (CK) was $201 \mathrm{IU} / \mathrm{L}$ (normal range is up to $140 \mathrm{IU} / \mathrm{L}$ ). Serum C-reactive protein and KL6 were elevated to $0.49 \mathrm{mg} / \mathrm{dL}$ and $1383 \mathrm{U} / \mathrm{mL}$, respectively. Anti-nuclear autoantibody was positive $(\times 320$, speckled pattern) as well as anti-U1RNP antibody and anti-SSA antibody. Immunoprecipitation assays revealed the presence of antiEJ antibody. Chest X-rays and CT revealed diffuse ground glass or reticular shadows with honeycomb appearance in both lung fields, indicating the presence of ILD (Figure 1). Compared with previous CT imaging, however, obvious progression of ILD was not seen. Abdominal X-rays revealed multiple dilations of the small and large bowels, with air-fluid levels in bowel loops. Abdominal CT showed large distentions of the bowel in the absence of any mechanical obstruction (Figure 2(a)). As these findings strongly suggested relapse of myositis and CIPO, $20 \mathrm{mg}$ of PSL, gastrointestinal prokinetic agents, and antibiotics were started. Fever, muscle symptoms, serum CK, and dyspnea and hypoxia improved relatively rapidly. However, despite treatment via inserted gastric tube to administer metoclopramide (30 mg/day), pantethine $(90 \mathrm{mg} /$ day $)$, itopride hydrochloride $(150 \mathrm{mg} /$ day $)$, mosapride acid hydrate ( $15 \mathrm{mg} /$ day), daikenchuto ( $7.5 \mathrm{~g} /$ day), dimethicone $(120 \mathrm{mg} /$ day), lactulose $(60 \mathrm{~mL} /$ day $)$, magnesium oxide ( $2 \mathrm{~g} /$ day $)$, and erythromycin $(800 \mathrm{mg} /$ day $)$ for pseudoileus of CIPO, her bowel movement did not improve. In mid-March, we began continuous intravenous octreotide at $100 \mu \mathrm{g}$ for persistent CIPO. Soon after starting this treatment, peristaltic activity was detected, and subjective symptoms dramatically improved. Abdominal X-ray and CT also revealed that there was no thickening of the bowel wall and that dilation of the bowels with air-fluid levels was improved (Figure 2(b)). In the middle of April, although the route of octreotide administration was changed to subcutaneous (50 $\mu \mathrm{g}$ for every 6 hours), she had no abdominal pain or distention and was discharged from hospital. The patient was treated with intramuscular long-acting octreotide (30 mg every 4 weeks) as an outpatient. She was well and was maintained in a stable condition with no abdominal symptoms on octreotide. In March 2013, octreotide was discontinued because she had been well for over 2 years. In September 2015, she died from an acute cerebral hemorrhage.

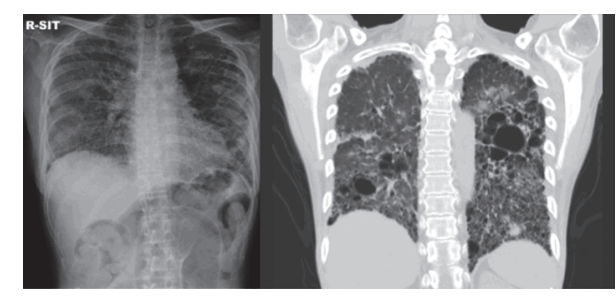

FIGURE 1: Chest radiography and CT findings at the emergent admission. Diffuse ground glass or reticular shadow with honey combing appearance in both lung fields.

\section{Discussion}

To the best of our knowledge, this is the first case of a patient with DM and anti-EJ antibody developing CIPO and then being successfully treated with octreotide. The CTD most commonly associated with CIPO is systemic sclerosis; the case of other CTDs who develop CIPO over their clinical course seems relatively rare. Our patient manifested muscle weakness and typical DM rash but no sign of swollen hands or scleroderma and no history of previous Raynaud's phenomenon. Immunological examination revealed the presence of anti-EJ antibody, a myositis-specific antibody (anti-aminoacyl-transfer RNA synthetase (ARS) antibody). Taking these findings together, the patient was diagnosed as having DM. Although PM/DM patients sometimes suffer from dysphagia due to muscle weakness, dysfunction of visceral muscle is rarely seen. In our case, muscle symptoms improved relatively promptly, but abdominal disturbances were persistent after the improvement of muscle inflammation. However, CIPO can be a complication of PM/DM. Marie et al. reported a PM patient with CIPO complications, but without any sign of scleroderma [4]. The etiology of CIPO associated with PM/DM is still unknown and further identification of patients such as the case reported here would be required to determine this. As the cause of CIPO is various and our patient was complicated with ILD, one might suspect that CIPO arose due to chronic hypoxia. However, it was not likely that chronic hypoxia was cause of CIPO because her respiratory condition at the onset of CIPO was stable (blood oxygen saturation ranged from 96 to $98 \%$ in room air) and no progression of ILD was suspected.

We summarize available clinical and immunological characteristics of CTD associated with CIPO and treated with octreotide in Table 1 [3-16]. Of 24 CTD patients with CIPO, there were 20 (83\%) with SSc or SSc/PM overlap syndrome, and of the remaining 4 two had SLE, one PM, and one $\mathrm{DM}$ (the latter, our case reported here). All patients received octreotide subcutaneously except for our case initially. This drug was effective for CIPO in 20 patients $(83 \%)$. Nineteen (79\%) had scleroderma, 15 (71\%) experienced Raynaud's phenomenon, and 12 (67\%) had ILD that might suggest the presence of fibrosis in the smooth muscle of the gastrointestinal tract. Twelve (50\%) and 14 (79\%) patients suffered from diarrhea and constipation, respectively. In our case, similar to most of the cases previously reported, gastrointestinal prokinetic agents or antibiotics did not improve 


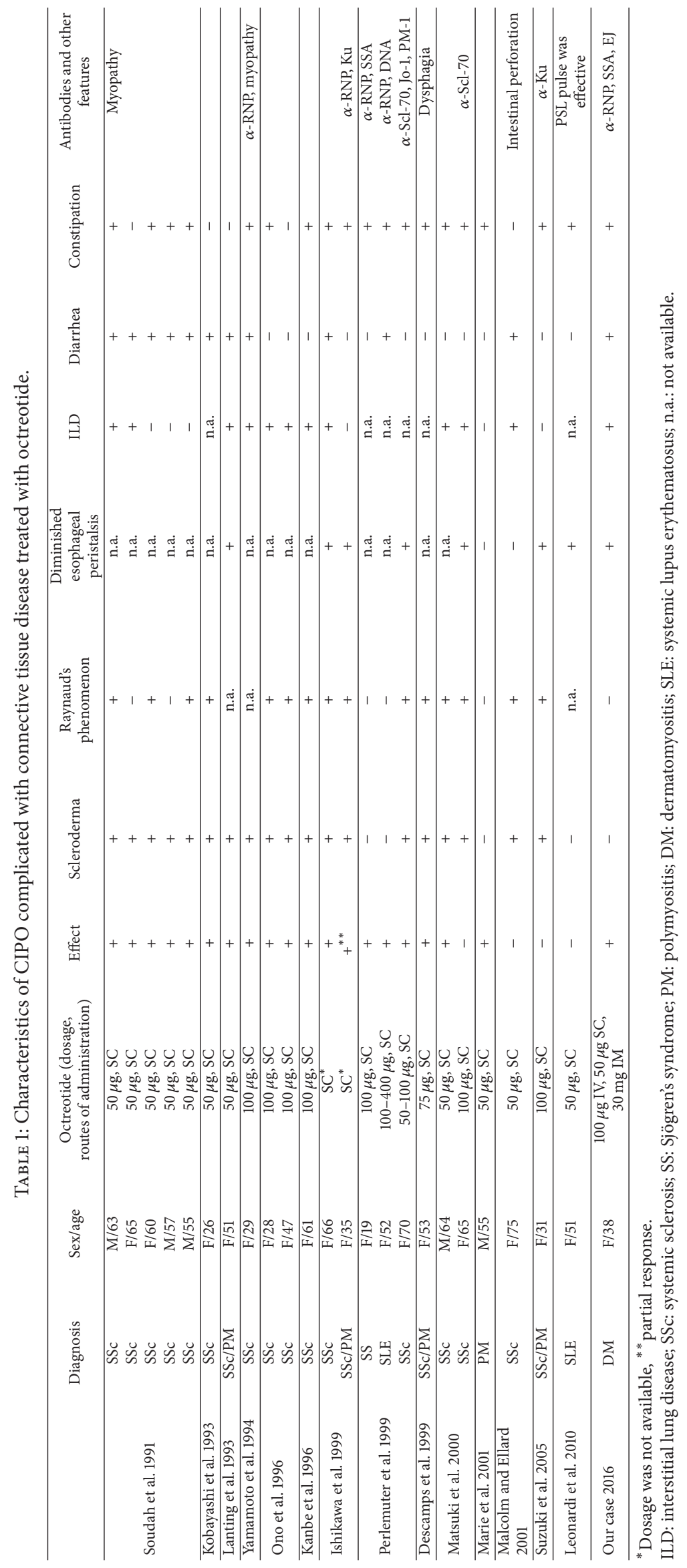




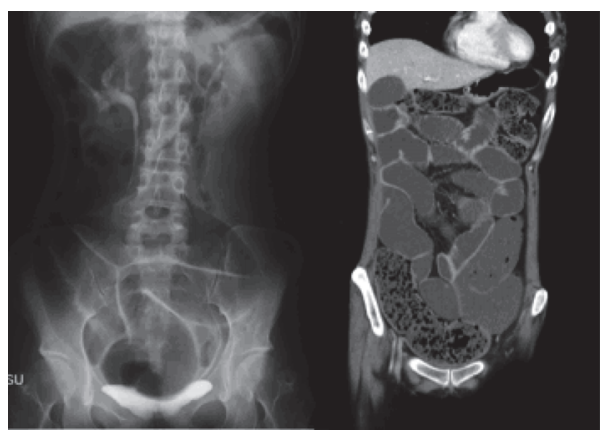

(a)

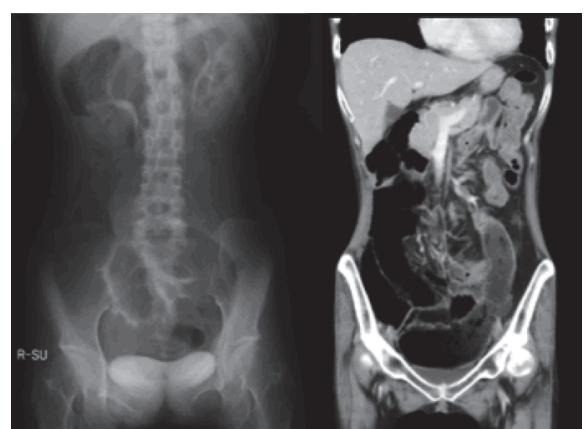

(b)

FIGURE 2: Abdominal radiography and CT findings at the emergent admission (a) and after treatment with octreotide (b). (a) Multiple and dilated small and large bowels with air-fluid levels in bowel loops (X-ray) and huge distention of bowel without mechanical obstruction (CT). (b) Thickening of the bowel wall and dilation of the bowels with air-fluid levels were improved.

abdominal manifestations. Therefore, we initiated octreotide intravenously, which resulted in improvement of CIPO. Although the administration route of octreotide in previous reports was subcutaneous or intramuscular [3-18], our case shows that continuous intravenous octreotide is also effective in CIPO associated with CTD. Moreover, experience with our case suggested that monthly subcutaneous administration of long-acting octreotide is also effective and has the advantage of ease of long-term management in the outpatient clinic. The efficacy and safety of octreotide in juvenile patients with CIPO was also reported [19]. The usefulness of antroduodenal manometry was suggested to evaluate octreotide response. Although we did not examine the manometry for the assessment of octreotide, the antroduodenal manometry would be a useful method to assess the effect of octreotide against CIPO.

In summary, here we report a DM patient with antiEJ antibody who developed persistent CIPO. In this case, intravenous administration of octreotide relieved abdominal symptoms and subsequent application of long-acting octreotide achieved prolonged complete remission. Thus, this case emphasizes the importance of being aware of the possibility of CIPO in patients with DM, as well as documenting the efficacy of continuous intravenous octreotide.

\section{Competing Interests}

There are no competing interests regarding the publication of this paper for all authors.

\section{Acknowledgments}

The authors thank Ms. Miyako Nakagawa and Etsuko Iwata for assisting with the immunoprecipitation assay.

\section{References}

[1] C. M. Pearson, "Inflammatory Myopathies: Polymyositis and dermatomyositis in," in Arthritis and Allied Condition : A Textbook of Rheumatology, 14th Philadelphia, Lea and Febiger, D.
J. McCarty, Ed., pp. 1562-1589, Arthritis and Allied Condition, A Textbook of Rheumatology, 2001.

[2] D. L. Faulk, S. Anuras, and J. Christensen, "Chronic intestinal pseudoobstruction," Gastroenterology, vol. 74, no. 5, part 1, pp. 922-931, 1978.

[3] H. C. Soudah, W. L. Hasler, and C. Owyang, "Effect of octreotide on intestinal motility and bacterial overgrowth in scleroderma," The New England Journal of Medicine, vol. 325, no. 21, pp. 14611467, 1991.

[4] I. Marie, J. M. Kerleau, P. Ducrotte et al., "Intravenous immunoglobulins and octreotide as treatment of intestinal pseudo-obstruction revealing a recurrence of polymyositis," Rheumatology, vol. 40, no. 9, pp. 1072-1073, 2001.

[5] T. Kobayashi, M. Kobayashi, M. Naka, K. Nakajima, A. Momose, and M. Toi, "Response to octreotide of intestinal pseudoobstruction and pneumatosis cystoides intestinalis associated with progressive systemic sclerosis," Internal Medicine, vol. 32, no. 7, pp. 607-609, 1993.

[6] P. J. H. Lanting, M. W. M. Kruijsen, J. J. Rasher, F. H. J. van den Hoogen, A. M. T. Boerbooms, and L. B. A. van de Putte, "Severe intestinal pseudoobstruction in a patient with systemic sclerosis. Successful treatment with octreotide," The Journal of Rheumatology, vol. 20, no. 12, p. 2175, 1993.

[7] T. Yamamoto, H. Fukuro, Y. Sawada, H. Yokozeki, I. Katayama, and K. Nishioka, "Successful treatment of scleroderma bowel with octreotide," The Japanese Journal of Dermatology, vol. 104, no. 6, pp. 793-797, 1994 (Japanese).

[8] M. Ono, K. Watanabe, T. Aikoh et al., "Effects of octreotide acetate treatment for scleroderma bowel," Kawasaki Medical Journal, vol. 22, no. 4, pp. 233-237, 1996 (Japanese).

[9] N. Kanbe, S. Warita, Y. Nagai, A. Tamura, O. Ishikawa, and Y. Miyachi, "Refractory ileus associated with systemic sclerosis successfully treated with octreotide," Rinsho Derma, vol. 38, no. 4, pp. 567-570, 1996 (Japanese).

[10] M. Ishikawa, J. Okada, and H. Kondo, "Five cases of systemic sclerosis with associated with intestinal pseudo-obstruction," Ryumachi, vol. 39, no. 5, pp. 768-773, 1999 (Japanese).

[11] G. Perlemuter, P. Cacoub, S. Chaussade, B. Wechsler, D. Couturier, and J.-C. Piette, "Octreotide treatment of chronic intestinal pseudoobstruction secondary to connective tissue diseases," Arthritis \& Rheumatism, vol. 42, no. 7, pp. 1545-1549, 1999. 
[12] V. Descamps, X. Duval, B. Crickx, F. Bouscarat, B. Coffin, and S. Belaich, "Global improvement of systemic scleroderma under long-term administration of octreotide," European Journal of Dermatology, vol. 9, no. 6, pp. 446-448, 1999.

[13] M. Matsuki, S. Motomura, H. Kita et al., "Two cases of progressive systemic sclerosis complicated with intestinal pseudoobstruction," Kyushu Journal of Rheumatology, vol. 19, pp. 78-81, 2000 (Japanese).

[14] A. Malcolm and K. Ellard, "Intestinal perforation associated with octreotide therapy in scleroderma," The American Journal of Gastroenterology, vol. 96, no. 11, pp. 3206-3208, 2001.

[15] C. Suzuki, M. Ohara, M. Yamamoto et al., "A case of scleroderma-polymyositis overlap syndrome in which octreotide exacerbated abdominal symptoms," Nihon Rinsho Meneki Gakkai Kaishi, vol. 28, no. 1, pp. 56-61, 2005 (Japanese).

[16] G. Leonardi, N. de Bortoli, M. Bellini et al., "Intestinal pseudo-obstruction in inactive systemic lupus erythematosus: an unusual finding," World Journal of Gastrointestinal Pharmacology and Therapeutics, vol. 1, no. 6, pp. 135-136, 2010.

[17] G. N. Verne, E. Y. Eaker, E. Hardy, and C. A. Sninsky, "Effect of octreotide and erythromycin on idiopathic and sclerodermaassociated intestinal pseudoobstruction," Digestive Diseases and Sciences, vol. 40, no. 9, pp. 1892-1901, 1995.

[18] G. C. Nikou, C. Toumpanakis, C. Katsiari, D. Charalambopoulos, and P. P. Sfikakis, "Treatment of small intestinal disease in systemic sclerosis with octreotide: a prospective study in seven patients," Journal of Clinical Rheumatology, vol. 13, no. 3, pp.119123, 2007.

[19] L. Ambartsumyan, A. Flores, S. Nurko, and L. Rodriguez, "Utility of octreotide in advancing enteral feeds in children with chronic intestinal pseudo-obstruction," Pediatric Drugs, vol. 18, no. 5, pp. 387-392, 2016. 


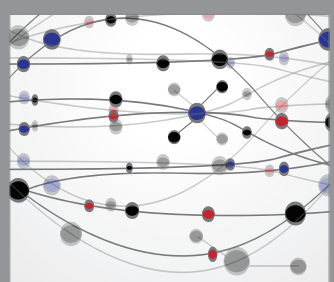

The Scientific World Journal
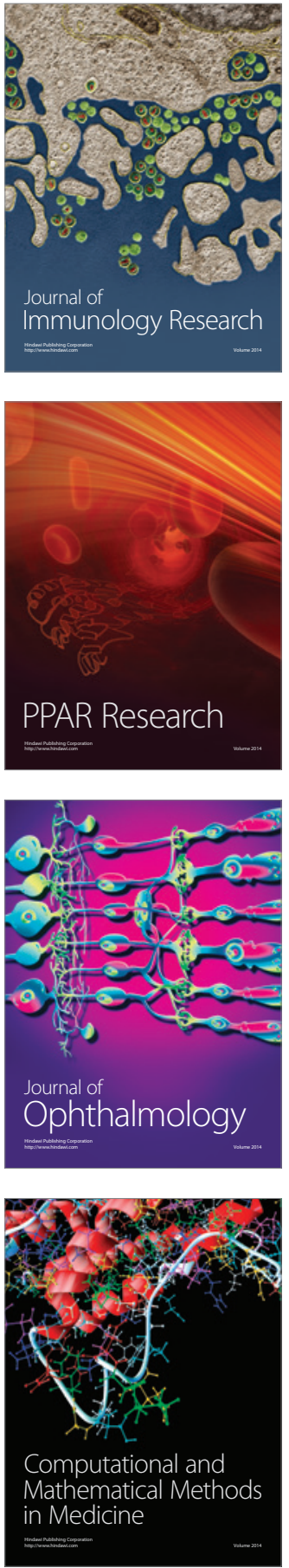

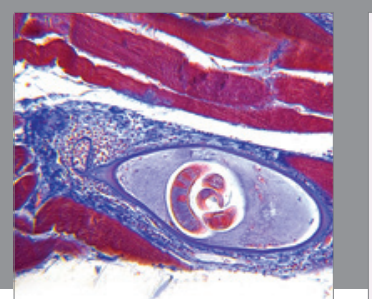

Gastroenterology Research and Practice

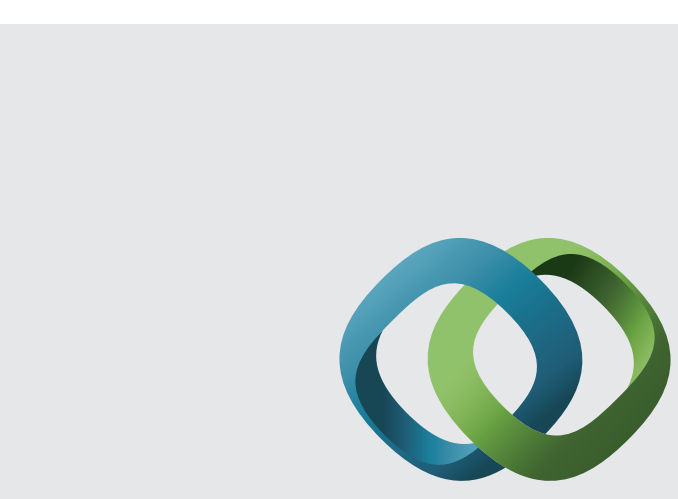

\section{Hindawi}

Submit your manuscripts at

http://www.hindawi.com
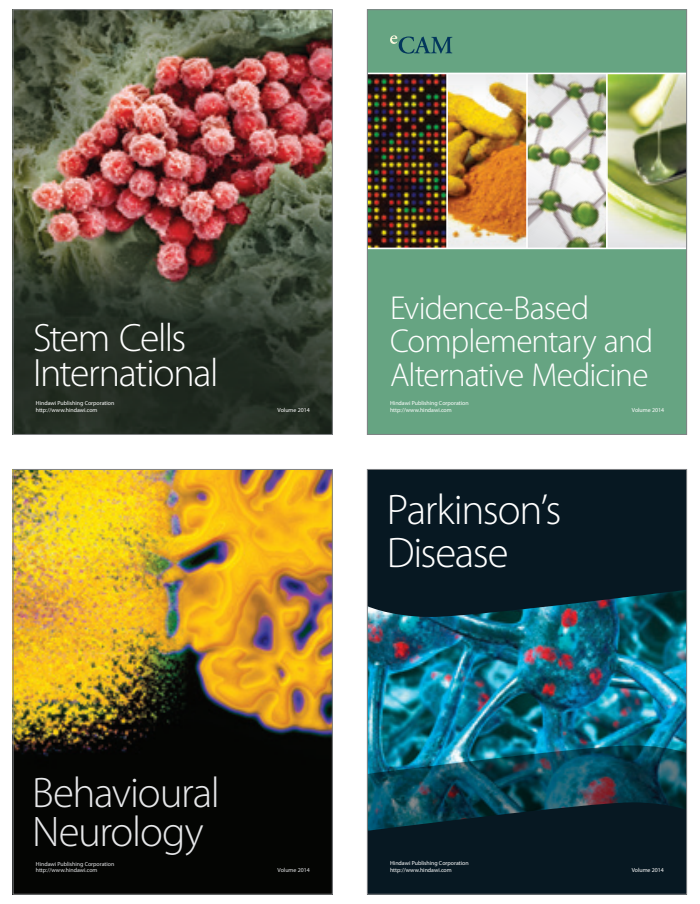
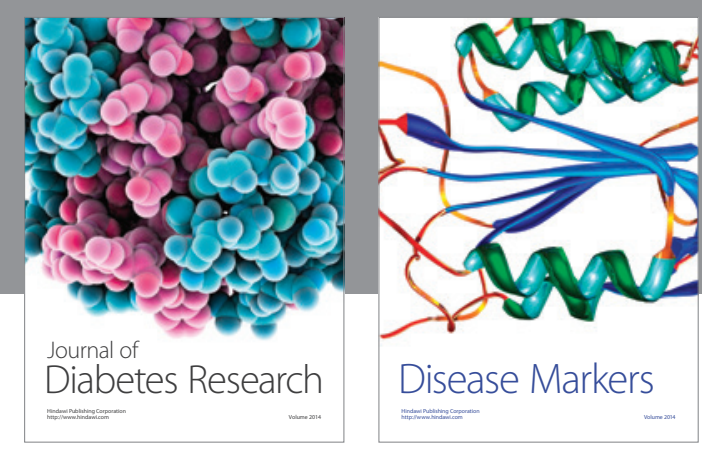

Disease Markers
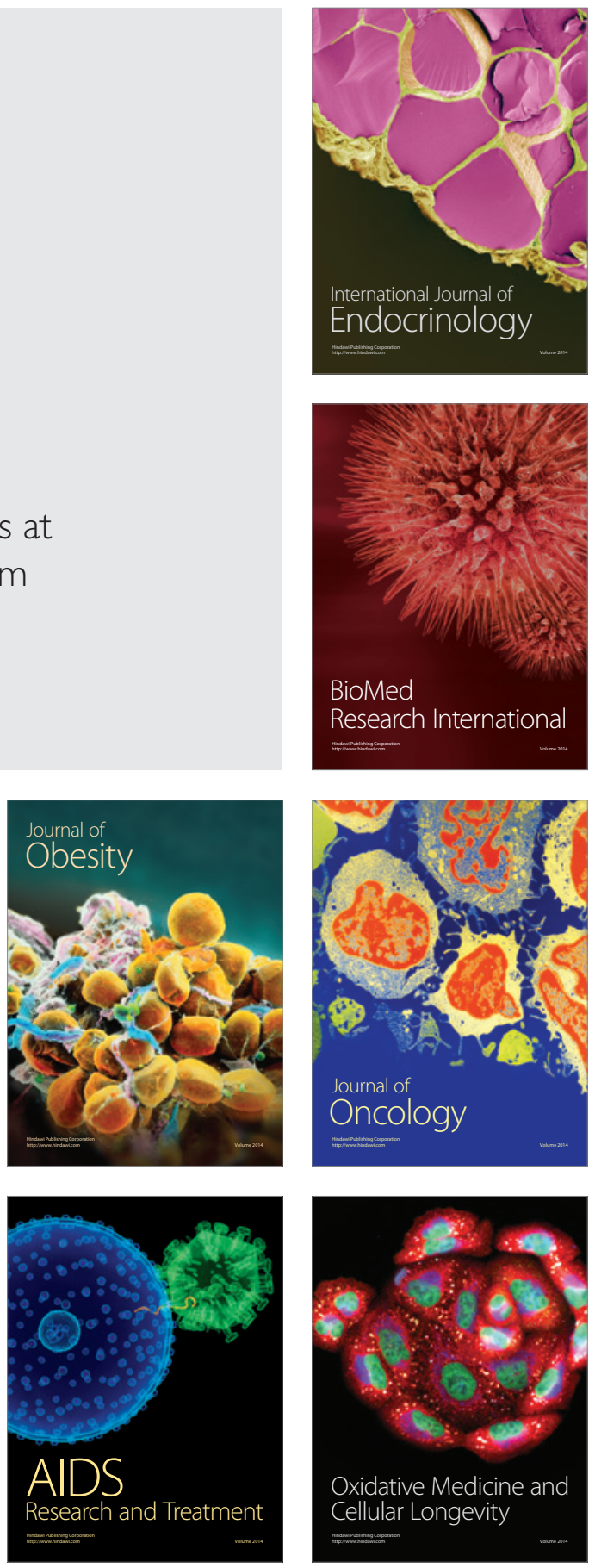